scouring (which does not produce a noxious effluent) is the most attractive to mills where this scouring method is acceptable.

The sessions were admirably chaired by Dr. E. G. Carter and Dr. G. Laxer of the International Wool Secretariat, Mr. W. A. May of the Australian Wool Scourers' Association and Dr. F. G. Lennox of the
C.S.I.R.O. Division of Protein Chemistry. The papers were followed by lively discussion, which contributed considerably to the success of the colloquium.

The lectures will be published in full in the next few issues of the Textile Journal of Australia.

C. A. Anderson

G. F. WOOD

\title{
HIGH-TEMPERATURE DYEING
}

A HALF-DAY conference on "Continuous High-temperature Dyeing" was held at the Shirley Institute, Didsbury, Manchester, on November 18. The conference consisted of two lectures given by staff from the Institute, each followed by an interval for discussion. In a joint paper, entitled "The Principles and Scope of Continuous High-temperature Dyoing", Mrs. B. J. Bonwitt and Mr. M. G. Corless dealt with the technical requiremonts of the process and the range of fibres and dyestuffs to which the technique is applicable. The differences between American and European practice were described. Whereas in America processing speeds are usually of the order of at least $100 \mathrm{yd} . / \mathrm{min}$, in Europe it is uncommon for speeds to exceed $30 \mathrm{yd} / \mathrm{min}$. The difference in approach can be ascribed to the difference between the structures of the two industries. Rather surprisingly it appears that machinery designed to run at lowor speeds has to be somewhat more refined than that designed for high-speed operation.

In the second paper, entitled "Modern Continuous Dyeing Machinery", Mr. L. J. Gibson reviewed the machinery at present available from Continental machinery makers and then went on to discuss economic factors. 'Thermosol' and pressure steam ranges are not economical for short runs. In general 4,000-5,000 yd. must be regarded as the minimum length at one shade; runs in the United States are commonly of the order of $20,000 \mathrm{yd}$., and $10,000 \mathrm{yd}$. is regarded as a minimum.

'Thermosol' machinery is being used primarily for the dyeing of polyester/cotton blends; padding systems are not yet sufficiently well developed to deal with the majority of continuous filament synthetic fabrics. Pressure steam ranges are only just coming into use and are primarily used for continuous filament viscose rayon fabrics. However, they show considerable promise for the dyeing of woven nylon fabrics. It seems certain that a major reorganization of the merchanting system will have to take place before continuous high-temperature dyeing can be exploited to the full, despite its many technical attractions.

The questions which followed both lectures led to discussions on continuous preparation. the desirability or otherwise of heat-setting betore padding, the merits of infra-red pre-drying and several other points. A moasure of the interest in the subject of the conference lies in the fact that 160 people accepted invitations to attend (the conference had to be repeated on November 19, it being impossible to accommodate all on one day). In addition to members of the Shirley Instituto, ropresentatives wero present from the major Continental machinery and dyestuff manufacturers.

\section{BIOENERGETICS}

\begin{abstract}
A SYMPOSIUM on "Bioenergetics" was held at the University of Western Ontario, London, Canada, during October 15-16 under the auspices of the Biochemistry Division of the Chemical Institute of Canada. The papers dealt, in three successive half-day sessions, with onergy transformations in the plant, microbial, and animal kingdoms. Interest in the symposium was evident from the attondance: 225 scientists wore present from places as far away as Halifax, Edmonton and California.

One of the highlights of the meeting was the afterdinner speech by Dr. R. Y. Stanier (University of California) on comparative aspects of the cytological structures involved in energy transformations. Most aerobic bacteria possess no recognizablo intracellular membrane components comparable with mitochondria. While it is possible to isolate fragments (presumably derived from outer cytoplasmic membranes) which contain oxidative enzymes, it is probably correct to view the whole bacterial cell as the smallest respiratory unit. The forms of photosynthetic structures present great variety in procaryotic cells. The chromatophores of the purple bacteria resemble the internal lamellæ seen in chloroplasts of higher forms. Tho lamellæ may appear as intrusions of the cytoplasmic membrane, as vesicular elements in the cytoplasm, or as transitions between the two forms. These primitive structural analogues of the chloroplast may be interpreted as early experiments on the path to evolution of the discrete. membrane-contained organelles of present-day higher organisms.

Mechanisms and intermediates of the phosphorylation reactions associated with photosynthesis were explored by Dr. D. I. Amon (University of California) and Dr. A. T. Jagendorf (Johns Hopkins University). Central to these
\end{abstract}

and subsequent discussions on photosynthesis was the role of ferredoxin, a low-molecular-weight protein containing stoichiometric proportions of non-hæm iron and sulphide, and possessing a redox potential at physiological $p \mathrm{H}$ in the neighbourhood of that for the hydrogen electrode. One of the more interesting functions of this strongly reducing electron carrier is its ability to promote net synthesis of pyruvic acid from acetyl coenzyme $\mathrm{A}$ and $\mathrm{CO}_{2}$, a reaction of especial significance to Chromatium where the primary products of photosynthesis are amino acids. The photoreduction of ferredoxin by activated chlorophyll appears to be a primary reaction in photosynthesis leading to generation of high-energy phosphate compounds, the production of reduced pyridine nucleotides for $\mathrm{CO}_{2}$-fixation, and the evolution of molecular oxygen. By alternating light and dark periods of exposure of isolated chloroplasts it is possible to demonstrate formation in the light of a high-energy compound with a short half-life which is capable of later transferring its energy equivalents to ATP in the dark. The nature of the intermediate is not estab. lished as yet, but its formation is associated with structural changes in the chloroplast and the uptake of hydrogen ions. Dr. Jagendorf provided some illuminating specula. tions concerning the relationship of these events to the known contractile changes of mitochondria and the anisotropic membrane ATPase theory of Mitchell.

The primary event of photosynthesis, the quantumtrapping, charge-separating mechanism which leads ultimately to the splitting of water into molecular oxygen and reducing equivalents of hydrogen, was described by Dr. N. E. Good (Michigan State University) and Dr. B. Kok (Research Institute for Advanced Studies, Baltimore). The process appears to involve an aggregate of 
chlorophyll molecules, which acts as a light-gathering structure analogous to a lens, transferring and focusing the energy from a single photon to a photochemicallyactive electron sink. Kinetic studies, based on combinations of selective inhibitors of oxygen evolution with the photochemically active site, have shown that the aggregate unit possesses approximately 2,500 chlorophyll molecules for each active oxygen-producing site. Losses in the energy transfers are compensated by an extension of half-life of the activated pigment molecules; an additional factor extending the stability of the excited pigments involves reaction with an associated electron carrier (probably cytochrome $f$ ) in a charge transfer complex. The entire process of photosynthesis may be viewed as an extension of the life-time of energy storage forms, from the activated singlet state of chlorophyll (half-life about $10^{-8} \mathrm{sec}$ ) to roduced pyridine nucleotide (half-life about $1 \mathrm{sec}$ ).

The problem of energy-production in certain autotrophic bacteria was broached by Dr. W. W. Umbreit (Rutgers University) and Dr. H. Lees (University of Manitoba). Tho inability of obligate autotrophs such as Thiobacillus thio-oxidans to grow with carbon sources other than carbon dioxide is unexplained since the organism possesses a full complement of enzymes for glucose metabolism, and converts ${ }^{14} \mathrm{C}$-glucose into cellular protein. Thiobacillus can be adapted to survive in the absence of earbon dioxide in a glucose medium under certain conditions but does not remain viable. The reduction of pyridine nucleotide for fixation of carbon dioxide by Nitrobacter does not appear to proceed by a direct pathway, since the redox potential for the oxidation of nitrite to nitrate is too high to permit a direct coupling of the two reactions. The initial electron transfor is to cytochrome $c$; reduction of pyridine nucleotide occurs by an energy-requiring reversed electron flow from cytochrome $c$, a reaction demonstrated previously in mammalian mitochondria and also reported for Escherichia coli.

Studies of oxidative phosphorylation in Mycobacterium phle $i$ were described by Dr. A. F. Brodie (University of Southern California). The oxidation of malic acid by cytochrome-containing particles from this organism proceeds via two different enzyme reactions. The first is the typical pyridine nucleotide-linked dehydrogenase; the second path proceeds by a flavin-mediated reduction of a naphthoquinone. Depletion of particulate naphthoquinone by irradiation with long-wave ultra-violet light causes inactivation of oxidation and phosphorylation with a varioty of substrates. Rostoration of activity on addition of synthetic and natural quinones revealed two sites of interaction with the electron transport system for pyridine nucleotide-linked substrates, and an additional site for succinate. The session on bacterial energetics was fittingly concluded by Dr. R. M. Hochster (Department of Agriculture, Ottawa) with a discussion of some unsolved prob. lems in this area. Major difficulties in assessing the efficiency of oxidative phosphorylation in microbial systems arise from the presence of high phosphatase activity and the existence of by-passes in the oxidative reactions.

The dynamics of carbohydrate metabolism in mammalian cells was discussed by Dr. G. R. Williams (University of Toronto) and Dr. E. Shrago (University of Wisconsin). by continuous monitoring of ${ }^{14} \mathrm{CO}_{2}$ roleased from carboxyl-labelled substrates by respiring liver mitochondria in vitro, it was possible to calculate the rate constants for utilization of intermediates of the tricarboxylic acid cycle. The rate constant for fumaric acid was considerably greater than that for succinic acid, suggesting that succinic dehydrogenase is a limiting component of the cycle. On the in vivo level, studies of enzymes in animals rendered diabetic by alloxan treatment revealed marked alterations in pathways of carbohydrate motabolism. The most dramatic change was the marked incroase in activity of the soluble enzyme, phosphoenolpyruvic acid carboxykinase, in liver; since the increase was reversed by injection of insulin it would appear that this enzymo plays a major part in the endocrine regulation of gluconeogenesis.

Dissection of the mitochondrial oxidative phosphorylation process into its partial reactions was presented by Dr. C. L. Wadkins (Johns Hopkins University). A protein of low molecular weight which catalyses an exchange reaction between adenosine diphosphate and adenosine triphosphate may bo extracted from liver mitochondria; simultaneously, the phosphorylation coupled to cytochrome $c$ oxidation is abolished, and may be restored by addition of the purified exchange enzyme to the depleted mitochondria. The exchange onzyme appears to correspond in its action and properties to tho coupling factor III described by Green et al. Kinetic studies indicate that ferro-cytochrome $c$ combines at two sites on the exchange enzyme; interaction at one site is blocked by dinitrophenol, while azide or oligomycin $A$ prevents combinations at both sites.

Dr. W. Chefurka (Agricultural Research Institute, London) presented comparative data on the lability of phosphorylation reactions in mammalian mitochondria and insect sarcosomes. The rapid ageing of insect mitochondria is related to the rapid release of free fatty acids from mitochondrial lipids. The most sensitive indicator of the ageing process is the adenosine triphosphate cleavage occurring in the presence of dinitrophenol. The disappearance of the latter enzyme on ageing may be reproduced by in vitro addition of fatty acid.

The symposium was well organized by a local committeo under the chairmanship of Dr. K. P. Strickland. Fortunately, sufficient time was allowed for free discussion of the stimulating data and ideas presented in the formal papers. All present at the symposium were able to participate in several interesting functions concerned with nutrition, digestion, and the products of fermentation. Plans are under way to publish tho papors in the Canadian Journal of Biochemistry.

W. C. MCMURRAY

\section{OCEANOGRAPHY IN BRAZIL}

\begin{abstract}
THE recent symposium on the oceanography of the western South Atlantic organized by the Brazilian Academy of Sciences (Rio de Janeiro, September 14-18) was an important step in the dovelopment of tho investigation of the sea in South America. For many years there has been an activo interest in oceanography in Brazil. Initially this manifested itself in the establishmont of the Instituto Oceanografico in the University of São Paulo and the acquisition of field stations, one at Ubatuba situated close to an inviting range of sub-tropical marine environments, and the other at Cananéia amidst an extensive mangrove swamp with its exciting scientific problems. These facilities encouraged an energetic interest in marine biology.
\end{abstract}

The Brazilian contribution to the symposium strongly reflected this initial interest but also showed how widely the field of work has since developed. Other laboratories have entered the field, and the papers pre. sonted included investigations of the Brazil current, of water movemonts nearer to the coast, the drift of littoral sediments, the production of organic matter, the biology of the plankton and benthos, and geophysical investigations of the sea-bod.

Delegates from Argontina and other South Amorican countries contributed accounts of similar investigations extending southwards to the waters of the Antarctic, and it was clear that an important aspect of a meoting such as this lay in bringing together for the first time 